\title{
Scapula Winging With a Clavicle Fracture: A Case Report
}

\author{
Karunakgaran $\mathrm{K}^{1 *}$ and Taran Singh Pall Singh ${ }^{2}$ \\ Department of Orthopaedic, Malaysia. \\ *Corresponding author: Karunakgaran K, Department of Orthopaedic, Malaysia
}

Submission: 䟧 September 22, 2017; Published: 眥 May 18, 2018

\begin{abstract}
We report a case of a patient who sustained closed comminute mid-shaft right clavicle fracture with ipsilateral scapula winging. The winging persisted for 4 weeks after the fracture and spontaneously resolved after open reduction and internal fixation of right clavicle. We suspect that the winging is caused by scapular dyskinesia secondary to shortening of the clavicle.
\end{abstract}

\section{Introduction}

Clavicle fracture association with scapula winging is a rare entity. Prevalence of scapula winging in clavicle fractures is less than $0.05 \%$ [1]. Damage to the long thoracic nerve is a classic cause of medial scapula winging [2]. There are reports of scapula winging in association with malunions and non-union's of acromian fractures [3], as well as clavicle fractures [3].

\section{Case Report}

A previously healthy 21-year-old Malay girl presented to our clinic 6 weeks after sustaining a closed comminute mid-shaft right clavicle fracture following a motor vehicle accident. She had no other significant injuries. Examination revealed a deformity in the right mid-clavicular area and crepitus upon attempted shoulder motion. There was no evidence of brachial plexus injury clinically as her sensory and motor examination was all normal. She had limited shoulder abduction and flexion due to pain. Posterior, there was prominence of the medial border of the right scapula which was also displaced laterally (Figure 1).

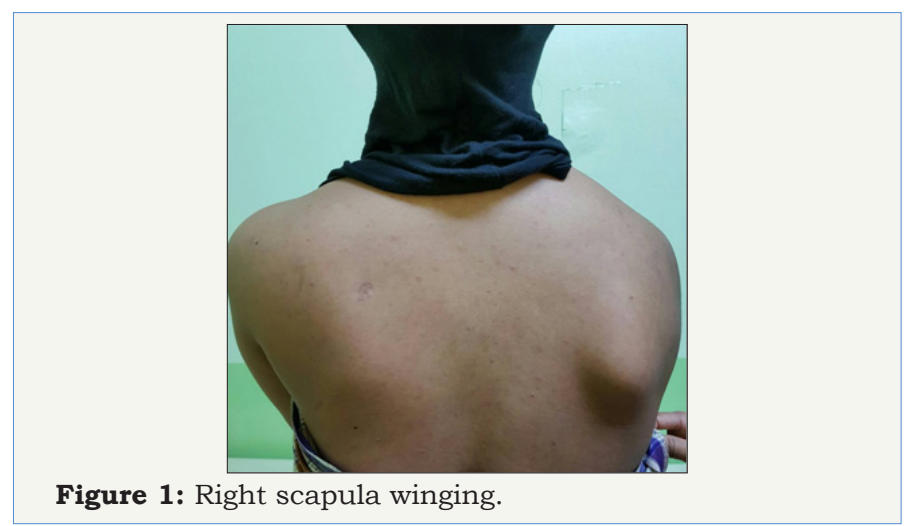

Upon pushing both palms against the wall with the elbows extended, the deformity disappeared. Specific assessment of the serratus anterior, trapezius and rhomboid muscles were normal. Nerve conduction study of the long thoracic and spinal accessory nerves was also normal. Radiographs revealed a displaced comminute clavicle shaft fracture with a shortening of $3 \mathrm{~cm}$ (Figure 2). The clavicle fracture was treated surgically with open reduction and internal fixation using a distal clavicle locking compression plate (Synthes $($ ) and augmented with autologous cortico-cancellous iliac crest bone graft (Figure 3). There was near complete resolution of the scapular winging upon inspection on the second day after surgery (Figure 4). The patient was also prescribed physiotherapy with emphasis on serratus anterior, rhomboid and trapezius muscle strengthening. On the first follow up after 2 weeks of surgery, complete resolution of winging. During second follow up after 2 months of post-operative, she had good shoulder range of motion.

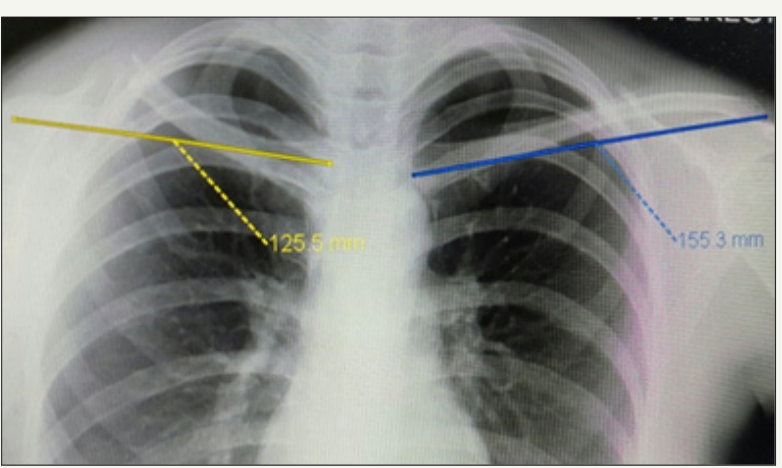

Figure 2: Chest radiograph showing right clavicle midshaft fracture with $3 \mathrm{~cm}$ shortening. 


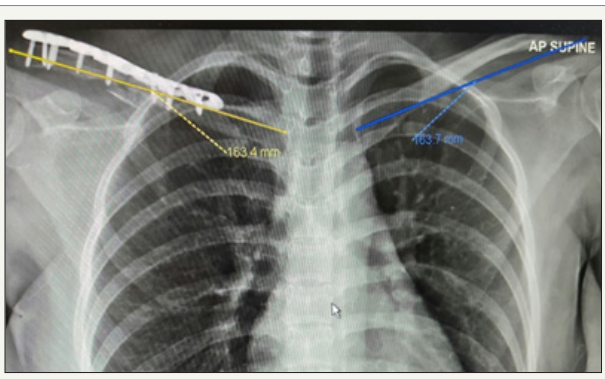

Figure 3: Post-operative Chest radiograph showing restoration of right clavicle length.

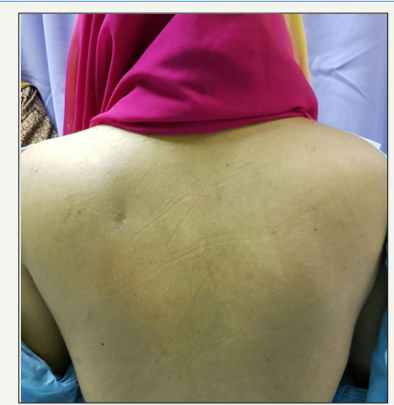

Figure 4: Right scapula winging resolved during inspection on the second day after surgery.

\section{Discussion}

Our patient presented with a unique case of scapula winging. We suspect that the winging is caused by scapular dyskinesia secondary to shortening of the clavicle. The clavicle acts as a strut for the shoulder complex, connecting the scapula to the axial skeleton. Alteration in this linkage may lead to abnormalities in the static or dynamic position of the scapula [4]. Dyskinesia can be a clinical sign of potentially harmful alteration of clavicle anatomy, hence, justifying surgical treatment for these fractures. In majority of these cases, scapula winging resolves completely after surgery. Other possible contibutory factors to produce winging with a clavicle fracture include loss of scapular suspensory mechanism and pain.

\section{References}

1. Kendra E Keenan, John G Skedro (2012) A Patient Clavicle fracture with recurrent scapula winging. Hindawi publishing corporation.

2. Fiddian NJ, king RJ (1984) The winged scapula clinical orthopaedic and related research.185: 228-236.

3. Rasyid HN, Nakajima T (2008) Winging of scapula caused by disruption of sternoclavicularscapular linkage. Journal of shoulder and elbow surgery.

4. Scapular dyskinesis. Scott Sevinsky MSPT.
Creative Commons Attribution 4.0 International License

For possible submissions Click Here

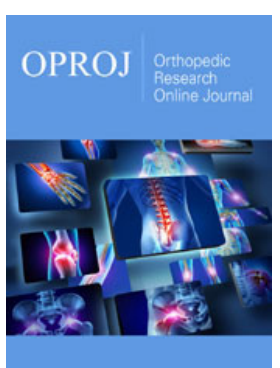

Orthopedic Research Online Journal

\section{Benefits of Publishing with us}

- High-level peer review and editorial services

- Freely accessible online immediately upon publication

- Authors retain the copyright to their work

- Licensing it under a Creative Commons license

- Visibility through different online platforms 